\title{
The Efficiency of Fly Ash Concrete in the Context of the Combined Action between Chlorides and Carbonation
}

\author{
Raphaele Malheiro $^{1}$, Gustavo Camacho ${ }^{1}$, Gibson Meira ${ }^{2}$ and Aires Camões ${ }^{1}$ \\ ${ }^{1}$ Centre for Territory, Environment and Construction (CTAC), University of Minho, Campus Azurém, \\ Guimarães, Portugal, raphamalheiro@gmail.com, gustavo92@live.com.pt, aires@civil.uminho.pt \\ ${ }^{2}$ Federal Institute of Education, Science and Technology of Paraíba, R. Dep. Balduíno M. de \\ Carvalho, 155/1104,58.036-860 João Pessoa, Paraíba, PB, Brazil, gibsonmeira@yahoo.com
}

\begin{abstract}
The fly ash concrete ( $F A C)$ has often been used in chloride contaminate environments. The aluminates present in fly ash (FA) react with free chlorides binding them and reducing the amount of chlorides able to penetrate into concrete. However, $\mathrm{Ca}(\mathrm{OH})_{2}$ present in $\mathrm{FAC}$ is easily consumed by pozzolanic reactions, making easier the advance of carbonation. In this context, it is important to know the FAC behaviour in environments subjected simultaneously to chlorides and carbonation. Chloride diffusion coefficient $(D)$ increases in environments containing chlorides and $\mathrm{CO}_{2}$ when compared to one containing only chlorides. This increase is related to the effects of carbonation on concrete. Therefore, this paper investigates the efficiency of FAC in context of the combined action of chlorides and carbonation. Two different concretes were cast, a FAC (40\% FA) and a reference concrete (RC), that is a concrete with similar properties to FAC but without FA. After 90 days humid curing, half of specimens were subjected to accelerated carbonation $\left(20^{\circ} \mathrm{C}, 55 \% \mathrm{RH}\right.$ and $\left.4 \% \mathrm{CO}_{2}\right)$ during 1,2 and 7 months. The other half was protected and remained in laboratory during the same period. Afterwards, non-steady-state migration tests were performed. The results show that, under the studied conditions, the efficiency of the FAC against chloride penetration is not affected when compared to the results obtained for $R C$. The carbonation depth in FAC is higher than in $R C$, but the D in FAC remain lower than in RC. This behaviour can be attributed to the higher capacity of FAC binding chlorides.
\end{abstract}

Keywords: Chloride, Carbonation, Fly Ash, Combined Action, Migration Test.

\section{Introduction}

The building sector plays a significant role in the global energy use and carbon emissions. The concrete is one of most consumed materials in the world and the annual worldwide $\mathrm{CO}_{2}$ emissions from cement manufacturing, main component of concrete, add up to almost 2.3 billion $\mathrm{mt}$, which is nearly $7 \%$ of the global emissions from fossil fuel combustion (Mehta \& Monteiro, 2014). To reduce the environmental impact of the building sector is essential to reduce the cement consumption and to guarantee the long-term durability of concrete structures.

The incorporation of fly ash (FA) in cementitious matrices has been used in two main ways. First, to reduce the cement consumption without loss of mechanical strength. Second, to increase the concrete structures durability, making its cementitious matrix more resistant to the action of chlorides. The $\mathrm{SiO}_{2}$ present in FA reacts with $\mathrm{Ca}(\mathrm{OH})_{2}$ resulting from cement hydration and produces $\mathrm{C}-\mathrm{S}-\mathrm{H}$ structures that strongly decrease the concrete porosity and hence reduces the transport of aggressive agents such as chloride ions. In addition, the aluminates present in FA chemically react with free chlorides binding them and reducing the amount of free chlorides able to penetrate into concrete (Alonso Alonso, Acha and Andrade, 1994). 
Therefore, the FA concrete has showed a high perform in chloride presence (Cheewaket, T., Jaturapitakkul, C. and Chalee, 2010; Chindaprasirt, Rukzon and Sirivivatnanon, 2008; Varga, I., Spragg, R., Bella, C., Castro, J., 2014). However, the consumption of $\mathrm{Ca}(\mathrm{OH})_{2}$, due to the pozzolanic reactions, decreases the alkalinity of the concrete and resulting in a more rapid carbonation when compared to a concrete made without FA (Neville, 1997). In this sense, it is necessary to investigate the efficiency of FA concrete in the context of the environment containing chlorides and carbon dioxide.

In the present work, an experimental investigation is carried out to understand the behaviour of FA concrete against the coupled effect of chloride and carbonation. The effect of carbonation on chloride diffusion coefficient is evaluated.

\section{Experimental Program}

\subsection{Materials and Concrete Mixtures}

Ordinary Portland Cement (OPC), CEM I 42.5R, and FA were used as binder materials in the concrete specimens, which chemical compositions are presented in Table 1 . The chemical composition of FA was determined using x-ray fluorescence spectroscopy. In addition, Scanning Electron Microscopy was used to observe FA morphology (Figure 1), revealing that it is mainly composed by cenosphere particles (Malheiro et al., 2018). These FA were obtained from the burning of South African and Colombian coal in Portuguese thermoelectric power
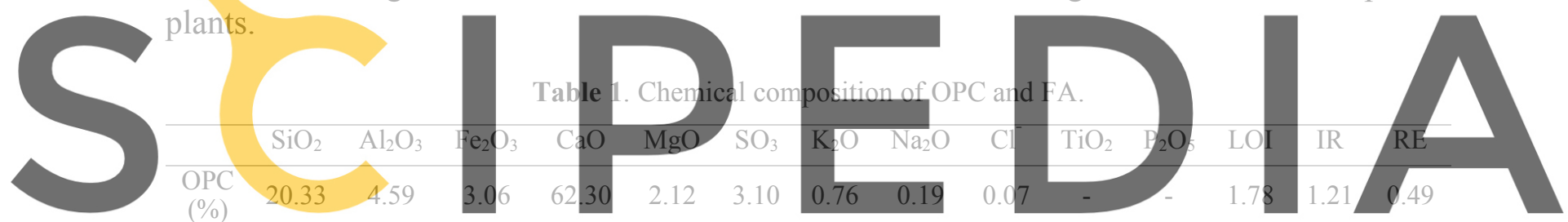

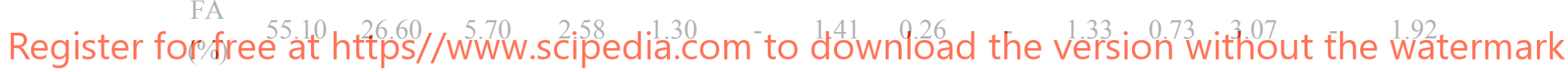

LOI - Loss on ignition IR - Insoluble residual RE - Remaining elements

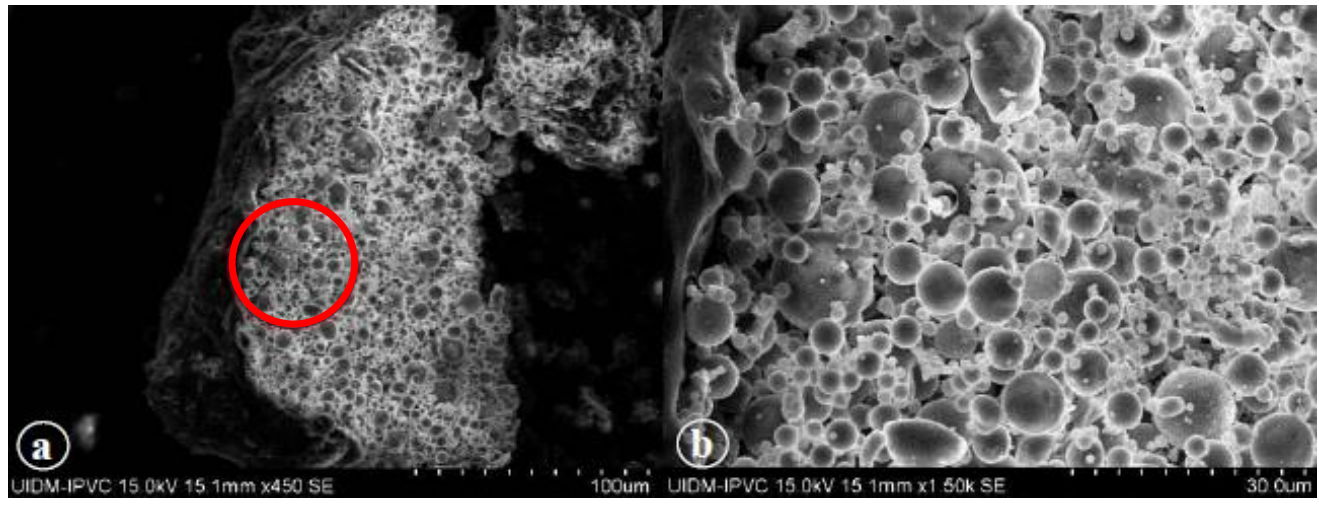

Figure 1. SEM FA images: $\mathrm{a}-100 \mu \mathrm{m}(\mathrm{x} 300)$ and $\mathrm{b}-30 \mu \mathrm{m}(\mathrm{x} 1500)$.

In addition to knowing the behavior of FAC under combined situation, it is also important 
to compare its behavior to $\mathrm{RC}$ behavior, that is a concrete with similar properties to FAC but without FA, under same situation. Thus, two mixtures were adopted in this study, which are presented in Table 2. Crushed sand with a fineness modulus of 2.96 and two types of granitic crushed coarse aggregate, one with fineness modulus of 6.07 and the other with 6.94, were used. Tap water, maximum value of chlorides in the water was $10 \mathrm{mg} / 1$, was used for mixtures.

Table 2. Materials and main properties of the mixtures.

\begin{tabular}{ccc}
\hline Properties & FAC & RC \\
\hline FA $(\%)$ & 40 & 0 \\
\hline Cement $\left(\mathrm{kg} / \mathrm{m}^{3}\right)$ & 228 & 380 \\
\hline FA $\left(\mathrm{kg} / \mathrm{m}^{3}\right)$ & 152 & 0 \\
\hline Water/binder ratio & 0.50 & 0.50 \\
\hline Slump $(\mathrm{mm})$ & 110 & 95 \\
\hline $\begin{array}{c}\text { Compressive strength } \\
\text { days }(\mathrm{MPa})\end{array}$ & 51.59 & 53.45 \\
\hline $\begin{array}{c}\text { Immersion water absorption } \\
(\%)\end{array}$ & 9.99 & 10.75 \\
\hline $\begin{array}{c}\text { Capillary water absorption } \\
\left(\mathrm{kg} / \mathrm{m}^{2} / \mathrm{min}^{1 / 2}\right)\end{array}$ & 0.116 & 0.104 \\
\hline
\end{tabular}

Cylindrical concrete specimens with $\phi 100 \times 200 \mathrm{~mm}$ were casted with the mixtures presented.

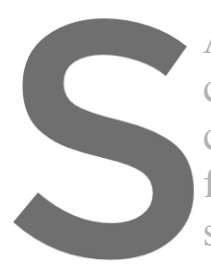
After casting, the specir chamber $\left(21^{\circ} \mathrm{C}\right.$ and $\left.98 \% \mathrm{RH}\right)$ for cured immersed in wate for pozzolanic reaction specimens were cut in three slices $(\phi 100 \times 50$
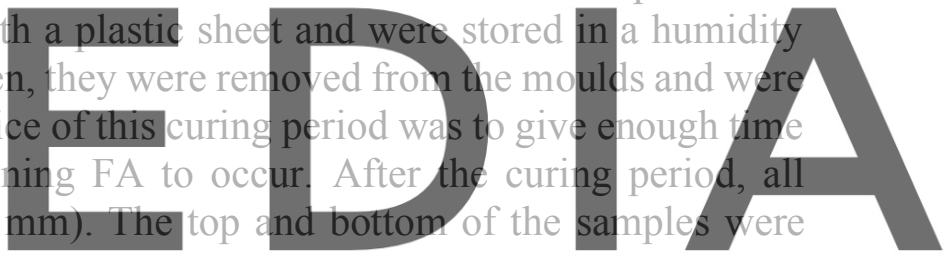
discarded.

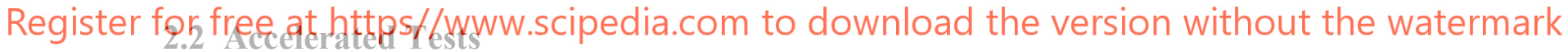

The efficiency of FAC in the context of the combined action between chlorides and carbonation was studied in two ways: combined situation and reference situation. In the combined situation the specimens were subjected to carbonation test and, after, to chloride migration test. In the reference situation, the specimens were subjected only to the chloride migration test. The Figure 2 shows the test scheme.

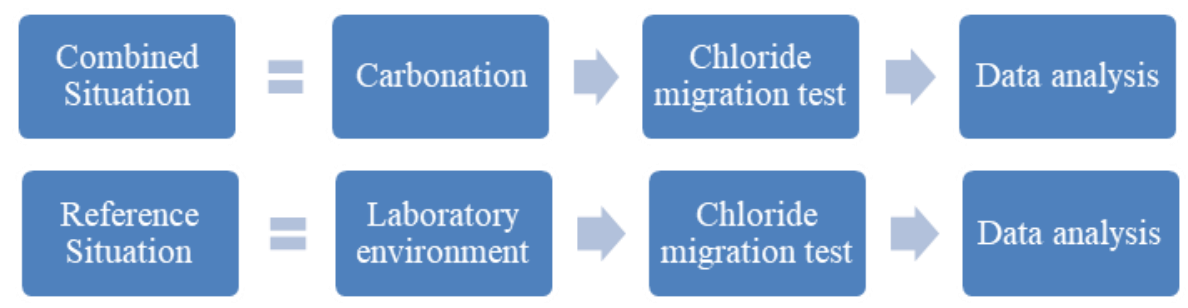

Figure 2. Laboratorial procedure scheme.

Before the tests, the specimens (FAC and RC) were subjected to preconditioning procedures 
in order to achieve the equilibrium with environmental humidity near $60 \%$ and accelerate the carbonation process (in the combined situation case). This preconditioning had three stages. In the first stage, the specimens remained in a chamber with controlled temperature and humidity $\left(20^{\circ} \mathrm{C}\right.$ and $\left.60 \% \mathrm{RH}\right)$ until reaching constant mass. Second, they had the lateral and the bottom face covered with paraffin in order to guarantee the one dimensional attack of aggressive agents through the top of the specimen. Third, in order to distribute the humidity inside the concrete specimens, they were protected with several layers of plastic film and put in a ventilated oven $\left(40^{\circ} \mathrm{C}\right)$, for 20 days. The specimens were weighed before and after being in oven and one has verified that the water loss was not bigger than $0.1 \%$.

In the combined situation, after preconditioning procedures, the plastic film was removed and the specimens were subjected to accelerated carbonation in carbonation chamber $\left(4 \% \mathrm{CO}_{2}\right.$, $20^{\circ} \mathrm{C}$ and $55 \% \mathrm{RH}$ ), following the recommendations of the European Standard (CEN/TS1239012, 2010), during three different periods: 1,2 and 7 months. Finished the test, the specimens were not broken and the paraffin coating was removed in order to permit the chloride migration test to be carried out. In the reference situation, the specimens remained wrapped in laboratory environment $\left(20^{\circ} \mathrm{C}\right.$ and $\left.60 \% \mathrm{RH}\right)$ until chloride migration test time.

After, the chloride migration test was performed according the Portuguese specification (LNEC E 463, 2004). Finished the test, the specimens were broken perpendicular to the penetration direction of the aggressive agents. In the combined situation, the specimens were tested after each carbonation period studied. In this case, the halves were used in different ways: one half was sprayed with a solution of 1\% phenolphthalein in 70\% ethyl alcohol (RILEM TC CPC-18, 1988) in order to determine the carbonated fromt and the other hrlf was sprayed with
0.1 $\mathrm{N} \mathrm{AgNO}_{3}$ to determine the chloride penetration depth. In the reference situation, the hal ver
were used to determine the chloride penetration depth.
2.3 Capillary Water Absorption Test

The capillary water absorption test was carried out in order to study the open porosity of

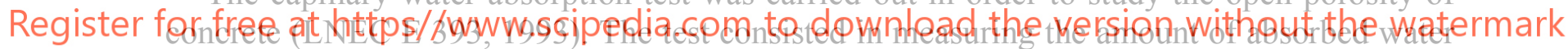
through only one face of a no saturated concrete specimen immersed in a water film of $5 \pm 1$ $\mathrm{mm}$. The absorption of water through capiliarity is the difference between concrete hardened mass, $\mathrm{M}_{\mathrm{i}}(\mathrm{g})$, that had one face in contact with water during a time ti and the dry concrete mass, $\mathrm{M}_{0}(\mathrm{~g})$, divided by the superficial area that was in contact with water, a $(\mathrm{mm})$.

\section{Results and Discussion}

\subsection{Effect of Carbonation on the Chloride Diffusion Coefficient in Specimens with FA Incorporation}

The effect of carbonation on the chloride diffusion coefficient in FAC is evaluated in Figure 3. This figure gathers the chloride diffusion coefficient values achieved for concrete subjected to the combined situation and reference situation. The values were determined for the three different carbonation test periods studied: 1, 2 and 7 months. 


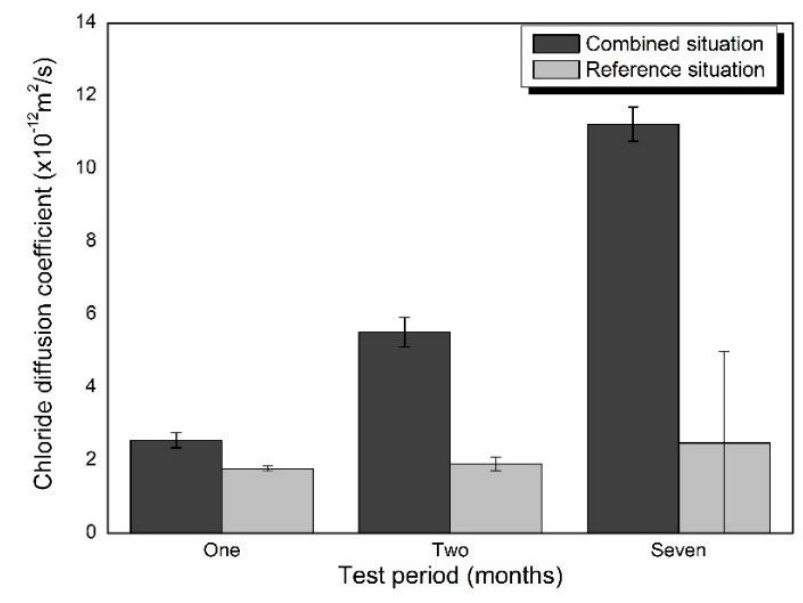

Figure 3. Chloride diffusion coefficient for FAC for the different situations: combined and reference.

According Figure 3, under conditions studied, there is a significant increase in chloride diffusion coefficient for FAC subjected to the combined situation when compared to the reference situation. This increase is quite high since the first month and gradually increases, until reaching the value of $352 \%$ in the seventh month.

The relationship between chloride diffusion coefficient and carbonation depth for FA concretes studied is showed in Figure 4. In this case, the chloride diffusion coefficient is closely

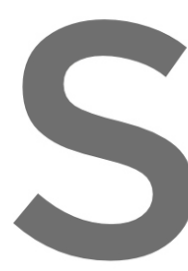

related to the carbonati

determination, $\mathrm{R}^{2}=0$

significant increase in
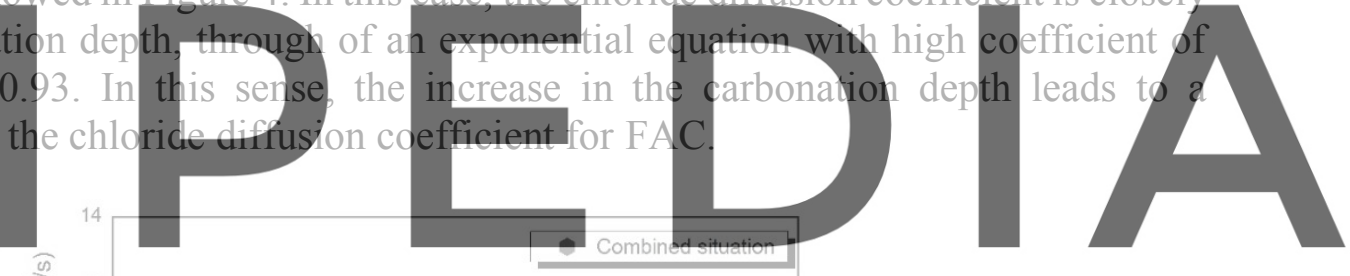

Register for free at https//wVin.scipedia.com to download the version without the watermark

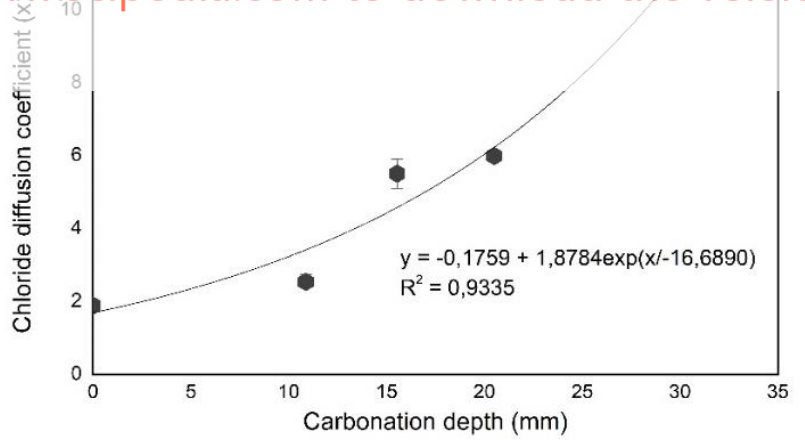

Figure 4. Relationship between chloride diffusion coefficient and carbonation depth for FAC.

The increase in the chloride diffusion coefficient can be related to: the increase in the large capillary pores, caused by carbonation (Ngala, V. and Page, 1997), which, in this case, can provides a "privileged path" for the chlorides penetration; and the chloride binding capacity reduction in carbonated concrete, consequently, there are more free chlorides available to penetrate in the cementitious matrix. The hypothesis of the increase in the large capillary pores 
is investigated through the study of open porosity. The Figure 5 shows the capillary absorption results, after seven months, for FAC.
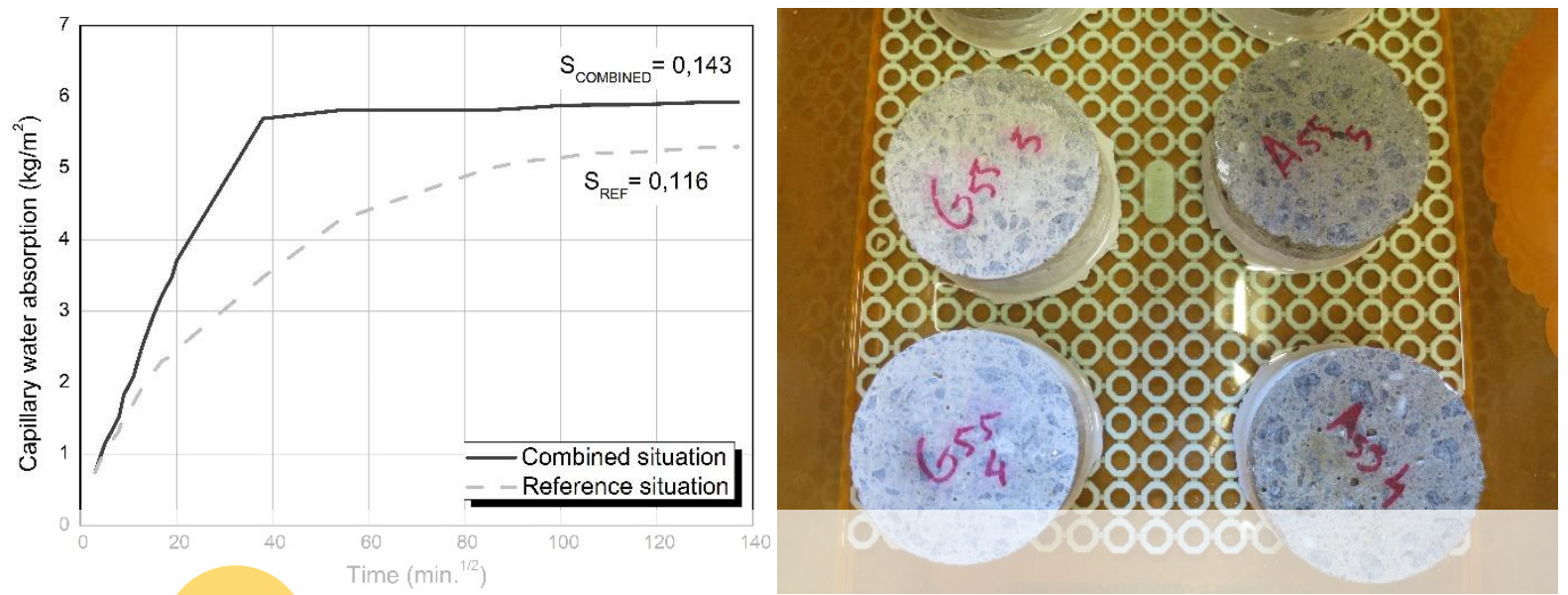

Figure 5. Capillary water absorption kinetics (left) and capillary water absorption test (right) after seven months testing.

In Figure 5 (left) is observed a higher capillary absorption coefficient for the specimens under combined situation when compared to the specimens under reference situation. It can

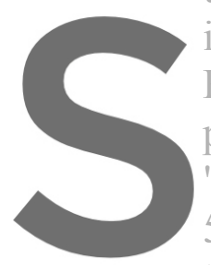

indicate an increase in the fration of the large capillary pores in FA concrete carbonated. Furthermore, the specimens subjected to the combined situation reached the stability pore saturation) more quickly, around 4.0 min "superficial perspiration" verified in the specinnens subjected to the combined situat 5, right) can be related to this capillary pore saturation. The results corroborate the hyp thesis that the increase in the large capillary pores was one of the responsible for the increase in the

Register for cride penetration in the carbonated FAC work as a "privileged path" for the free chlorides penetration. This path can be seen in FAC specimens after combined test (Figure 6): XM1 is carbonation depth (left) and XM2 is chloride penetration depth (right). The chlorides completely cross the carbonated front, XM1, but only penetrate a few millimeters (XM2 - XM1) after this front.

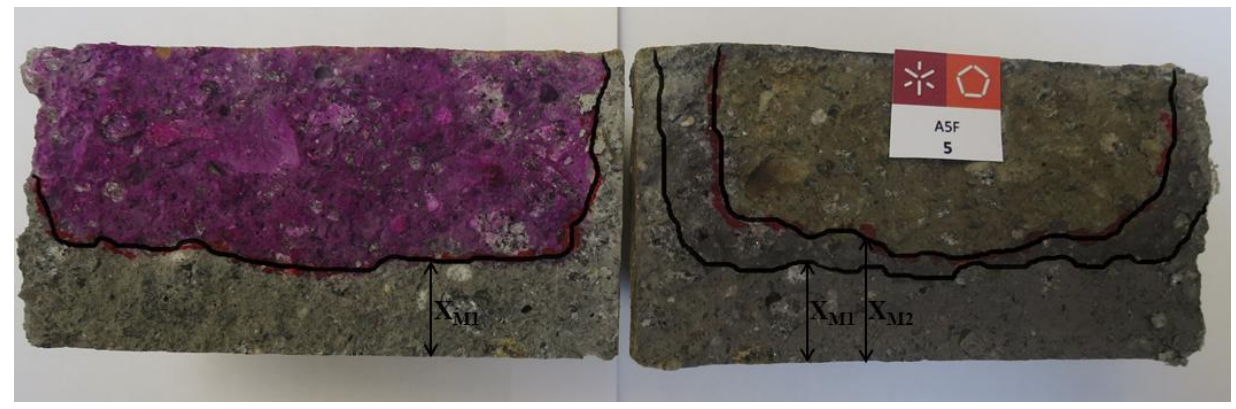

Figure 6. FAC specimens after combined situation (carbonation plus migration test). 


\subsection{Comparison between the Results Obtained for Specimens with FA Incorporation and Equivalent Specimens without FA}

It is important to understand the FAC behavior in environments containing chloride and carbon dioxide but it also important to compare its performance to RC performance in the same environment. The Figure 7 gathering the chloride diffusion coefficients and the carbonation depths achieved for these two types of concrete in different test periods.
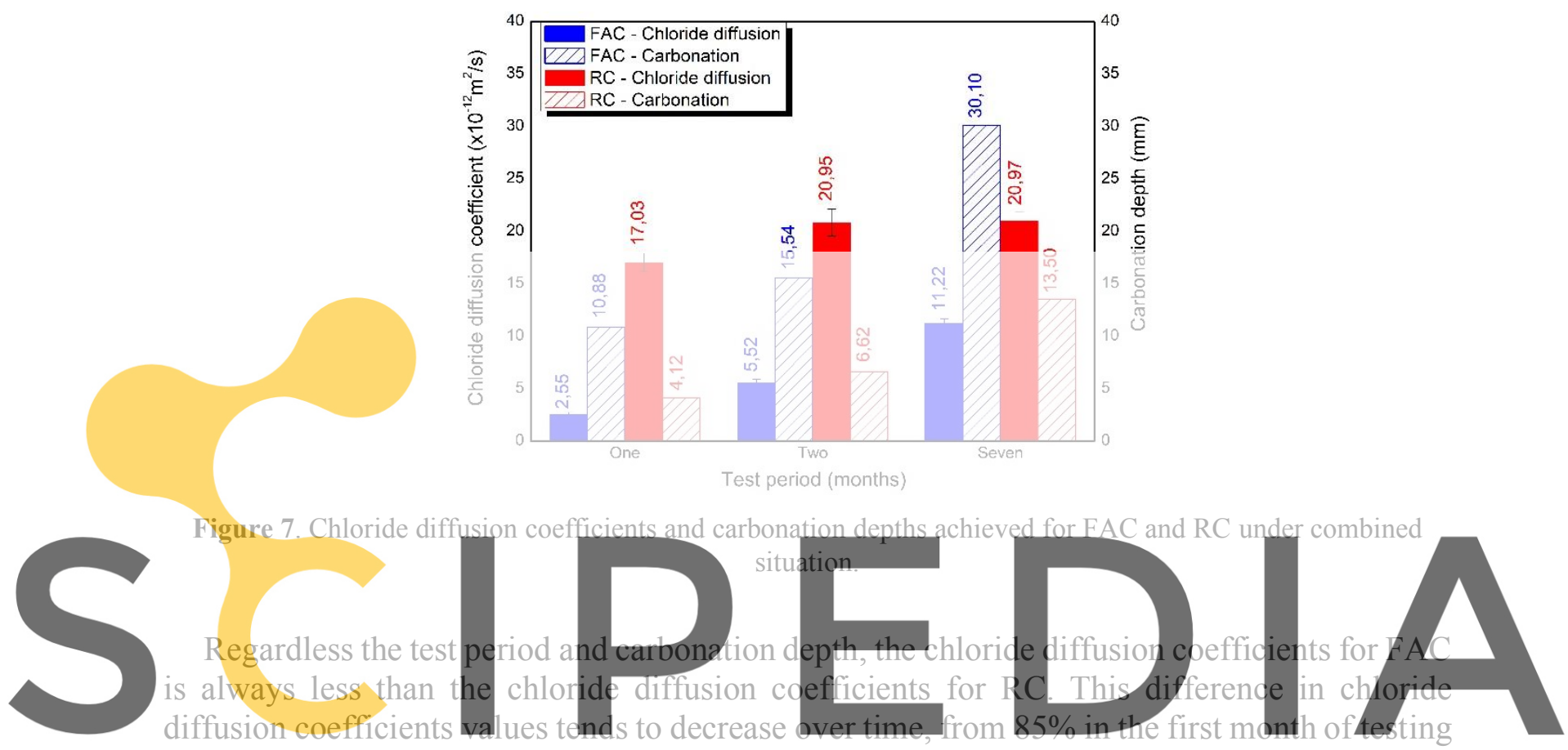

to $53 \%$ in the seventh month (it is still a very significant difference). This result corroborates

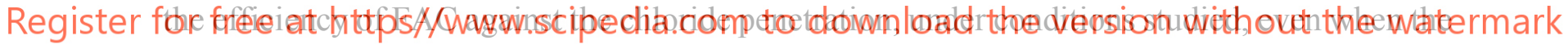
concrete structures are inserted in environments subject to chloride ions and carbon dioxide.

However, it is important to note that, regardless the test period, the carbonation depths for $\mathrm{FAC}$ is always higher than the carbonation depth for $\mathrm{RC}$. In the seventh month, the carbonation depth for FAC is very close $30 \mathrm{~mm}$. Taking into account the minimum coatings recommended by standards for carbonation environment, 25 - $40 \mathrm{~mm}$ (LNEC E 464, 2007), in this case, carbonation front can be close to the concrete reinforcement.

\section{Conclusions}

By experimental investigations on FAC subjected to chloride and carbonation environment, under conditions studied, the main conclusions can be drawn:

- There is a significant increase in chloride diffusion coefficient for FAC subjected to the combined situation when compared to the reference situation. This increase is related to the carbonation depth through an exponential relationship.

- This increase can be related to the increase in the large capillary pores, caused by carbonation, and the chloride binding capacity reduction in carbonated concrete.

- Despite the increase mentioned above, under chloride and carbon dioxide presence, the 
chloride diffusion coefficient for FAC is always less than the chloride diffusion coefficient for RC. However, the carbonation depth is significant.

\section{Acknowledgements}

The authors thank the Foundation for Science and Technology (FCT) for supporting this research. The au-thors also thank the SECIL for making available cement used in this research and the CIMENTEIRA DO LOURO for providing the aggregates used.

\section{ORCID}

Raphaele Malheiro: https://orcid.org/0000-0001-6922-9813

Gibson Meira: http://orcid.org/0000-0003-4473-4308

Aires Camões: https://orcid.org/0000-0002-9677-3627

\section{References}

Alonso Alonso, M. C., Acha, M. and Andrade, P. (1994). Incidencia de la adición de cenizas volantes en la durabilidad de las estructuras de hormigón armado. Hormigón y Acero, 45.

CEN/TS12390-12, E. C. for S. (2010). FprCEN / TS 12390-12 Testing hardened concrete - Part 12 : Determination of the potential carbonation resistance of concrete : Accelerated carbonation method.

Cheewaket, T., Jaturapitakkul, C. and Chalee, W. (2010). Long term performance of chloride binding capacity in fly ash concrete in a marine environment. Construction and Building Materials, 24, 1352-1357.

Chindaprasirt, P., Rukzon, S. and Sirivivatnanon, V. (2008). Effect of carbon dioxide on chloride penetration and chloride ion diffusion coefficient of blended Portland cement mortar. Construction and Building Materials, 22(8), 1701-1707. hittps://doi.org/10.1016/j.conbuildmat2007.06.002

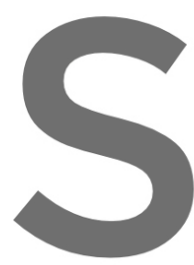

LNEC E 393. E 393 - Det

LNEC E 463. E 463 - Deter (2004). Lisbon: LNEC

LNEC E 464. E 464 - Concrete - Prescritive methodolo the environmental exposure (2007). Lisbon, Portugal

Malheiro, R., Camões, A.,Meira, G., Amorim, M. T.,

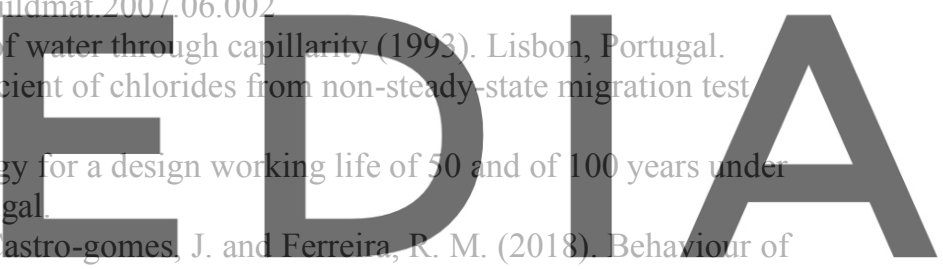
cementitious matrices subjected to the combined action of chloride ions and carbonation. Revista Materia,

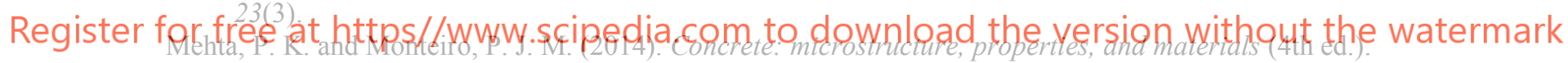
McGraw-Hill.

Neville, A. M. (1997). Propriedades of concrete (2nd ed.). São Paulo: PINI.

Ngala, V. and Page, C. (1997). Effects of carbonation on pore structure and diffusional propertiesof hydrated cement pastes. Cement and Concrete Research, 27, 995-1007.

RILEM TC CPC-18. (1988). RILEM RECOMMENDATION CPC-18 Measurement of hardened concrete carbonation depth. Materials and Structures, 453-455.

Varga, I., Spragg, R., Bella, C., Castro, J., B. D. and J. W. (2014). Fluid transport in high volume fly ash mixtures with and without internal curing. Cement and Concrete Composites, 45, 102-110. 